\title{
Oxidation Behavior of Ferritic Steel T22 Exposed to Supercritical Water
}

https://doi.org/10.1515/htmp-2018-0100

Received June 20, 2018; accepted September 29, 2018

\begin{abstract}
The oxidation tests of Ferritic Steel T22 exposed to supercritical water $(\mathrm{SCW})$ at $540-620^{\circ} \mathrm{C}$ and $25 \mathrm{MPa}$ was performed for up to $1000 \mathrm{~h}$. The oxidation rate increased with increasing exposure temperature and time. Oxide films formed on T22 have a double-layered structure with an outer layer consisting of iron oxide and an inner layer consisting of spinel oxide. Numerous pores on the surface can be observed at the initial oxidation stage while they seemed to heal with increasing exposure time at $620^{\circ} \mathrm{C}$. Cracks occurred along grain boundaries in the oxide scale when $\mathrm{T} 22$ exposed for $200 \mathrm{~h}$ at $620^{\circ} \mathrm{C}$. The influence of time and temperature on the oxidation of Ferritic Steel T22 was discussed.
\end{abstract}

Keywords: ferritic steel, oxidation, supercritical water, microstructure, temperature

\section{Introduction}

At present, ultra-supercritical (USC) power units, in which the main steam pressure and temperature are higher than $25 \mathrm{MPa}$ and $620^{\circ} \mathrm{C}$, are widely used. Furthermore, supercritical water-cooled reactor (SCWR) concept is one of the Generation IV nuclear power plants chosen for further investigation and development in many countries. The main steam and reheat-steam temperatures are $540-600^{\circ}$ $\mathrm{C}$ and $540-620^{\circ} \mathrm{C}$, respectively [1]. The efficiency of SCWR can be improved to about $45-50 \%$. Advanced ultrasupercritical (AUSC) technology is the most promising

*Corresponding authors: Zhongliang Zhu, Electrical \& Electronic Engineering School, North China Electric Power University, Beijing 102206, PR China; Key Laboratory of Condition Monitoring and Control for Power Plant Equipment of Ministry of Education, North China Electric Power University, Beijing 102206, PR China,

E-mail: zhuzl@ncepu.edu.cn

Naiqiang Zhang, Key Laboratory of Condition Monitoring and Control for Power Plant Equipment of Ministry of Education, North China Electric Power University, Beijing 102206, PR China,

E-mail: zhnq@ncepu.edu.cn

Hasan Izhar Khan, Qi Cao, Key Laboratory of Condition Monitoring and Control for Power Plant Equipment of Ministry of Education, North China Electric Power University, Beijing 102206, PR China fossil power generation technology because of its high efficiency and reduction in pollutant emissions. The improvement in efficiency will require the higher temperature and pressure of steam in the high-temperature pipeline, which includes water wall, superheater and reheater. However, the higher steam parameter may accelerate the steam-side oxidation of metallic materials and result in exfoliation of oxide scale [2].

Different environmental factors such as temperature, pressure, dissolved oxygen (DO) play an essential role in determining the oxidation behavior of ferritic-martensitic steels. Zhang [3] made comparisons of the oxidation rate of P92 in supercritical water (SCW) with different DO contents and found that the weight gains of the ferriticmartensitic steel P92 increased with the DO for the concentrations from 100 to $2000 \mathrm{ppb}$ at $550^{\circ} \mathrm{C}$ under $25 \mathrm{MPa}$. $\mathrm{Xu}$ [4] also investigated the oxidation behavior of the ferritic steel T24 exposed to SCW at $600^{\circ} \mathrm{C}$ with three different DO contents (deaerated, 100 and $300 \mathrm{ppb).}$ Other authors [5-8] have reported the oxidation behavior of the T91, HT9 and HCM12A in SCW at $500^{\circ} \mathrm{C}$ under 25 $\mathrm{MPa}$ with the DO contents of 25 and $2000 \mathrm{ppb}$. The corrosion behavior of F-M steels in SCW at $400-600^{\circ} \mathrm{C}$ was investigated, and the oxidation rate increased observably with increasing exposure temperature [9]. The corrosion performance of $\mathrm{P} 92$ in SCW at $500-600^{\circ} \mathrm{C}$ under a pressure of $25 \mathrm{MPa}$ was also investigated [10]. Higher corrosion temperature resulted in a faster oxide growth, accompanied by oxide scale cracking. Angell [11] and Bischoff [12] studied the corrosion behavior of P92, HCM12A and NF616 alloys exposed to SCW and steam. The corrosion rate increased with an increase in exposure pressure. Although the influence of different environmental factors such as temperature, pressure and DO on the oxidation behavior of ferritic-martensitic (F-M) steels have been investigated. However, a few studies about the corrosion properties of Ferritic Steels in SCW above $600^{\circ} \mathrm{C}$ have been reported that depicts short-term or longterm overheating of boiler tubes. Notably, it is seldom to study the corrosion property of Ferritic Steel T22 in hightemperature SCW.

The oxidation behavior of F-M steel T22 in flowing SCW at $540-620^{\circ} \mathrm{C}$ under $25 \mathrm{MPa}$ was evaluated in this paper. The present work investigated the weight gain, 
phase structure, morphology and chemical composition of T22 exposed to SCW. Furthermore, the influence of time and temperature on oxide composition and the microstructure was also discussed.

\section{Experimental method}

The chemical composition of T22 is given in Table 1. Bulk T22 steel was cut into samples with a size of $25 \mathrm{~mm} \times 10 \mathrm{~mm} \times 2 \mathrm{~mm}$, which were polished by using $1 \mu \mathrm{m}$ diamond paste and then cleaned in acetone and deionized water. Oxidation tests in flowing deaerated SCW at 540$620^{\circ} \mathrm{C}$ were performed in a continuous SCW experimental facility at a pressure of $25 \mathrm{MPa}$ and flow rate of water was maintained at $5 \mathrm{~mL} / \mathrm{min}$ through a $5 \mathrm{~cm}^{2}$ cross-sectional area. Figure 1 shows the schematics of the SCW experimental facility. Ultra-pure water with an electrical conductivity of less than $0.1 \mu \mathrm{S} / \mathrm{cm}$ was obtained using an ion exchanger and used for the SCW experiments. The water was deaerated by heating to $100^{\circ} \mathrm{C}$ and bubbling pure nitrogen gas through it. The flow rate and pressure were controlled using a highpressure metering pump and a back-pressure valve. The samples were placed in an autoclave using platinum wires and ceramic insulators to avoid galvanic effects. The

Table 1: Chemical composition of the alloys (wt.\%).

\begin{tabular}{rrrrrrrrr}
\hline Alloy & C & Si & Mn & S & P & Cr & Mo & Fe \\
\hline T22 & 0.12 & 0.5 & 0.6 & 0.025 & 0.025 & 2.25 & 0.54 & Bal. \\
\hline
\end{tabular}

controlling methods for the DO content, pressure and temperature were described elsewhere [13].

Oxidation experiments were performed at $540 \pm 3^{\circ} \mathrm{C}$, $600 \pm 3^{\circ} \mathrm{C}$ and $620 \pm 3^{\circ} \mathrm{C}$ for $10 \mathrm{~h}, 80 \mathrm{~h}, 200 \mathrm{~h}, 400 \mathrm{~h}$, $600 \mathrm{~h}, 800 \mathrm{~h}$ and $1000 \mathrm{~h}$ at $620 \pm 3^{\circ} \mathrm{C}$ under a pressure of $25 \pm 0.2 \mathrm{MPa}$. For each test, the samples with a shorter exposure time were removed after their designed exposure period. The samples with a more extended exposure period were cooled to room temperature (in order to remove other samples) and reheated further to the testing temperatures to finish the tests. The samples were weighed before and after exposure using a Mettler Toledo balance with a sensitivity of $0.1 \mathrm{mg}$. The morphology and chemical compositions of the oxide films were analysed with a Jeol JSM 6490LV scanning electron microscope (SEM, Japanese electronics) equipped with an Oxford Instruments INCA energy dispersive X-ray spectrometer (EDS, Oxford). A theta-2 theta PANalytical X-ray diffraction (XRD, PANalytical B.V) system was employed to determine the crystal structure of the oxides.

\section{Results and discussion}

Figure 2 shows the experimental and the calculated weight gain data, which can be fitted using the following equation.

$$
\Delta w=k_{\mathrm{p}} t^{n}
$$

where $\Delta w$ is the weight change of T22 in $\mathrm{mg} / \mathrm{cm}^{2}, k_{p}$ is oxidation rate constant in $\mathrm{mg} /\left(\mathrm{cm}^{2} \mathrm{~h}\right), t$ is exposure time in $\mathrm{h}$, and $n$ is time exponent. Based on the Figure 2, it can

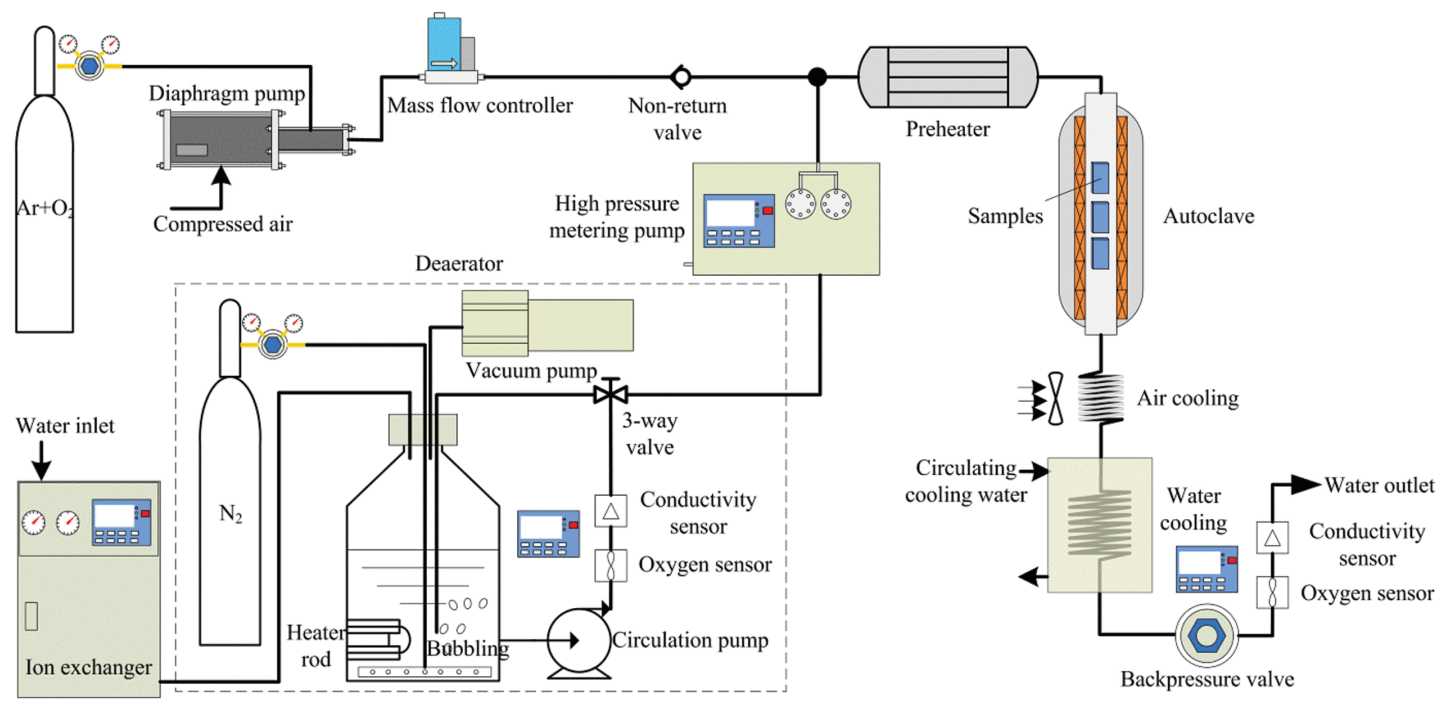

Figure 1: Schematic diagram of the SCW oxidation testing facility. 


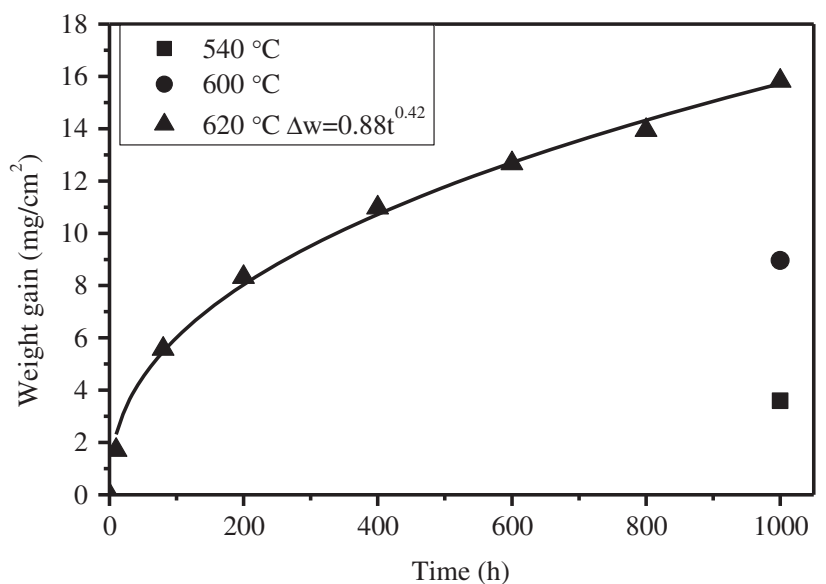

Figure 2: Weight gain for Ferritic Steel T22 sample as a function of time exposed in SCW at $540-620^{\circ} \mathrm{C}$ and $25 \mathrm{MPa}$. be found that the weight gain data follow a near-parabolic law at $620^{\circ} \mathrm{C}$. The weight gain of T22 steel for the exposure temperature $620^{\circ} \mathrm{C}$ is approximately 1.76 times greater than that for $600^{\circ} \mathrm{C}$ and the weight gain at 600 is approximately 2.5 times greater than that for $540^{\circ} \mathrm{C}$.

Figure 3 shows SEM micrographs of the oxide film morphologies formed on T22 exposed to SCW in the range $10-1000 \mathrm{~h}$ at $620^{\circ} \mathrm{C}$. Numerous pores formed on the surface of oxide can be observed after very short oxidation times, especially at $10 \mathrm{~h}$. However, the depth and amount of the pores on the surface decreased with an increase in oxidation time ( 80 and $200 \mathrm{~h}$ ). The pores were absent from the surface of oxide formed on T22 and the outer layer predominantly consists of coarse columnar grains after longer exposure time $(600 \mathrm{~h})$. The larger columnar grains can be observed with an increase in
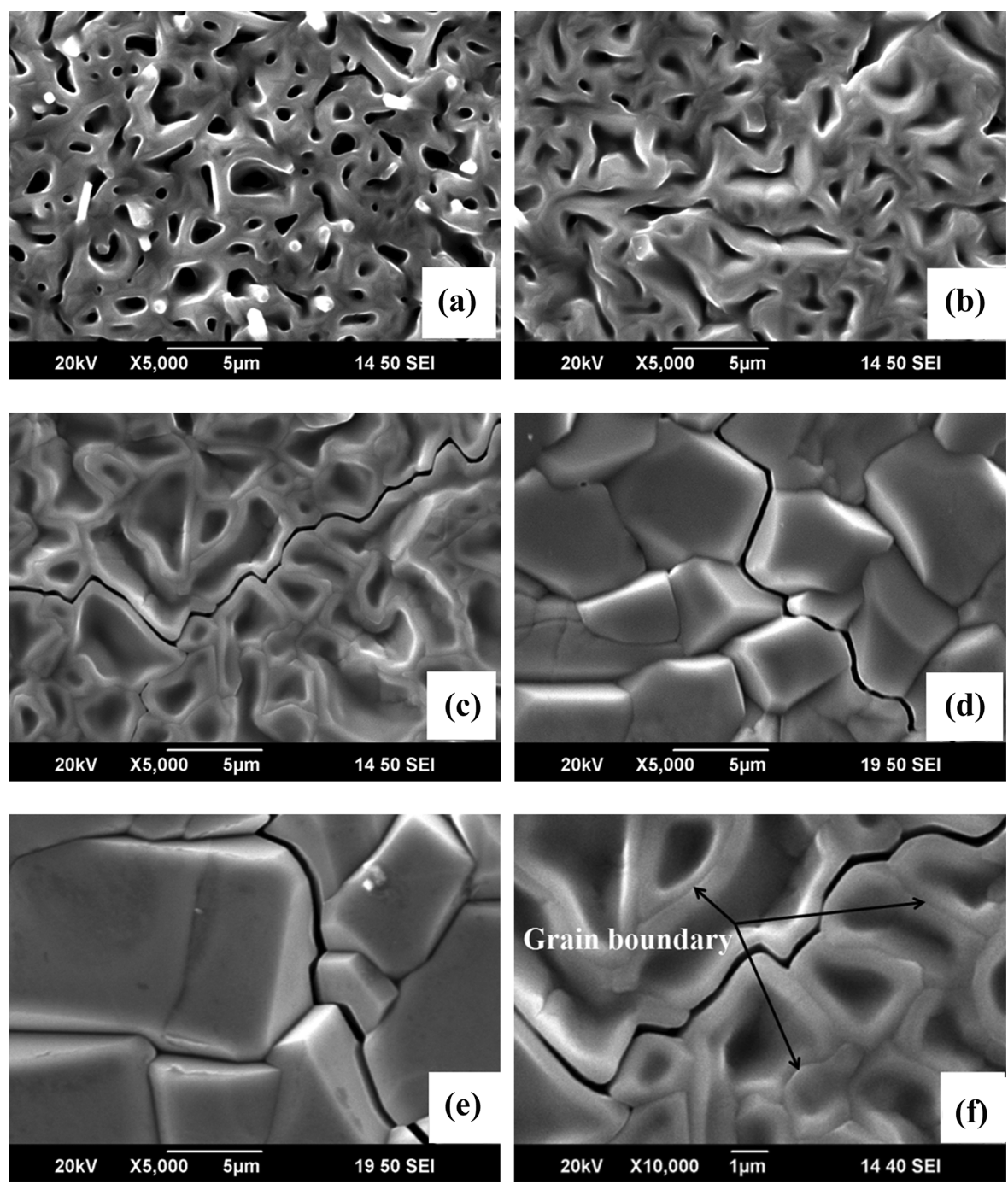

Figure 3: Surface scale morphologies of the oxide formed on Ferritic Steel T22 exposure to SCW at $620^{\circ} \mathrm{C}$ and $25 \mathrm{MPa}$. (a) $10 \mathrm{~h}$ (b) $80 \mathrm{~h}$, (c) $200 \mathrm{~h}$, (d) $600 \mathrm{~h}$ and (e) $1000 \mathrm{~h}$, (f) High magnification image of (c). 
exposure time (1000 h). Hence, it seems that there was a tendency for the voids to heal with increasing oxidation time. Likewise, the oxidation of P92 in SCW shows the similar phenomenon [14]. According to Figure 3(f), it can be seen that the oxide next to the grain boundary humps compared to the oxide located at the center of the grain. The oxidation mechanism of F-M steels in SCW has been discussed in several articles [4-6, 14]. It was proposed that outer oxides grow by predominant outward diffusion of metal ions with new oxide formation occurring at the oxide/SCW interface. The diffusion pathways of iron ion involve in grain bodies and grain boundaries. At the early stage of oxidation, high nucleation rate can lead to the formation of the outer oxide layer with small grain size. Smaller the grain size is, more the grain boundaries in the outer oxide layer are. Diffusion of metal ions along oxide grain boundaries is faster than lattice diffusion. The small grains can allow metal ions to more rapid transport to the surface of the outer oxide layer along oxide grain boundaries. It is possible that the oxide grows preferentially along grain boundaries at the early oxidation stage (see Figure $3(\mathrm{a}-\mathrm{c})$ ). However, the growth of the outer oxide layer is mainly dependent on outward diffusion of metal ions through the oxide lattice instead of via grain boundary diffusion at longer times because of the formation of large grains (see Figure 3(d) and 3(f). The transformation of the dominant diffusion path of the metal ion in the oxide scale may be responsible for the healing of the voids on the surface of the samples [14].

As shown in Figure 3(c-e), cracks formed along the grain boundaries of the outer oxide layer. Furthermore, the width of crack increased with an increase in time. Rhines [15] and Stringer [16] believed that an oxide layer formed on a flat surface by cation diffusion would grow preferentially into free space. Thus, growth stress would not develop on the scale. As a result, cracking may result from thermal stresses due to the different thermal expansion coefficients between the oxide and the metal during the cooling process.

Figure 4 shows the surface scale morphologies of the oxide formed on Ferritic Steel T22 at $540^{\circ} \mathrm{C}$ and $600^{\circ} \mathrm{C}$ exposed for $1000 \mathrm{~h}$. The oxide formed at $540^{\circ} \mathrm{C}$ for $1000 \mathrm{~h}$ was porous, but the pores disappear at $600^{\circ} \mathrm{C}$. No cracks are found in the scales at $540-600^{\circ} \mathrm{C}$ for $1000 \mathrm{~h}$ duration while cracks appear at $620^{\circ} \mathrm{C}$ on the scales formed after 200 h. According to Figure 3(e) and Figure 4, it can be observed that the grain size increased with the increase in exposure temperature.

The oxide phases of the T22 sample exposed to 540$620^{\circ} \mathrm{C}$ for $1000 \mathrm{~h}$ were identified by XRD and are shown in Figure 5. The XRD spectra indicated that the dominant phases in the oxide scale were similar, with magnetite $\left(\mathrm{Fe}_{3} \mathrm{O}_{4}\right)$ and spinel oxides $\left((\mathrm{Fe}, \mathrm{Cr})_{3} \mathrm{O}_{4}\right)$ being the only phases detected.

Figure 6 shows SEM images of morphologies of the oxide layers formed on T22 in SCW over a time range of $10-1000 \mathrm{~h}$ at $620^{\circ} \mathrm{C}$. The oxide scales typically consist of layers of a porous non-protective outer layer and the relatively compact inner layer. Using the EDS line-scan technique, the composition profiles across the thickness of the oxide layers are shown in Figure 7. The major element concentrations $(\mathrm{O}, \mathrm{Fe}$ and $\mathrm{Cr}$ ) display similar distributions in the oxide scale of the T22 samples at 10-1000 h. The EDS analyzing result shows that the outer oxide layer is primarily composed of $\mathrm{Fe}$ and $\mathrm{O}$ while the inner oxide layer consists of $\mathrm{Fe}, \mathrm{Cr}$ and $\mathrm{O}$ in three cases. Figure 8 shows the crosssectional morphology and the corresponding composition profiles of the T22 sample for $1000 \mathrm{~h}$ at $540-600^{\circ} \mathrm{C}$ in SCW. The oxide scale structure and chemical compositions of all samples tested at $540-600^{\circ} \mathrm{C}$ are same as that at $620^{\circ} \mathrm{C}$. Combining XRD and EDS analyses, the outer layer is a magnetite phase, and the inner layer is a $\mathrm{Fe}-\mathrm{Cr}$ spinel phase in all cases. Moreover, a diffusion layer existed between the oxide layer and the substrate, where the chemical compositions of all elements gradually changed from
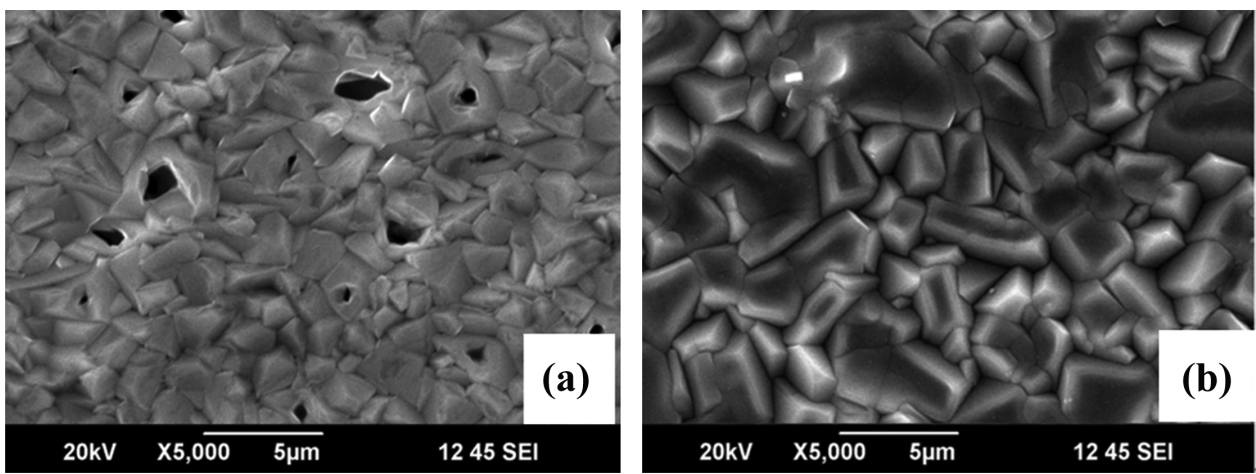

Figure 4: Surface scale morphologies of the oxide formed on Ferritic Steel T22 exposure to SCW for 1000 h. (a) $540^{\circ} \mathrm{C}$, (b) $600^{\circ} \mathrm{C}$. 


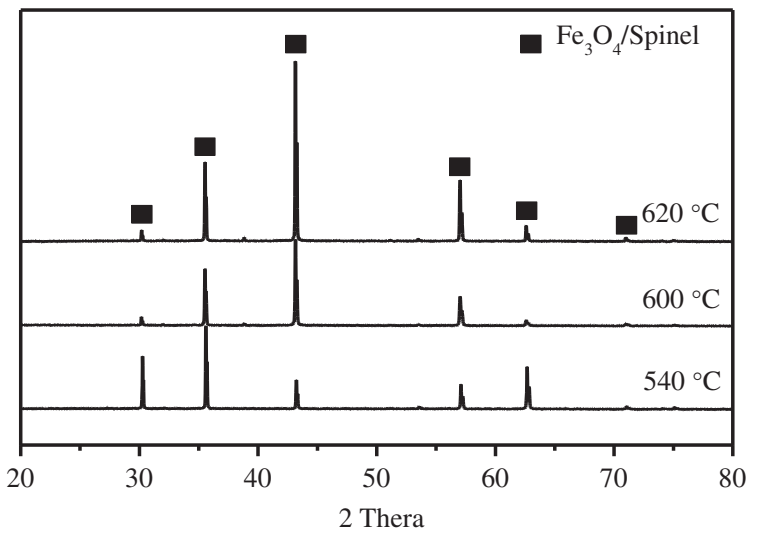

Figure 5: XRD patterns of samples exposed to SCW for $1000 \mathrm{~h}$.

that of the oxide to the bulk alloy concentration. As shown in Figures 6 and 8, a large number of pores formed in the outer layer. The porosity may be attributed to the formation of $\mathrm{Fe}_{3} \mathrm{O}_{4}$ phase. Magnetite has a spinel structure which consists of a closed-packed oxygen arrangement with the $\mathrm{Fe}^{2+}$ and $\mathrm{Fe}^{3+}$ ions on the tetrahedral coordination and the $\mathrm{Fe}^{3+}$ together with $\mathrm{Fe}^{2+}$ ions on the octahedral coordination. The O-rich non-stoichiometric composition of $\mathrm{Fe}_{3} \mathrm{O}_{4}$ in high-oxygen exposed samples can be presented as the major defect type and be regarded as the vacancies in the octahedral and interstitial sub-lattice [17]. When the vacancy concentration in magnetite is high enough, the vacancies may collapse into pores.

According to Figure 6 and Figure 8, it can be found that the interface of the inner layer and substrate is not straight and present a jagged outline. The phenomenon was observed by other authors $[18,19]$. The inner layer grew by oxygen diffusion preferentially along alloy grain boundaries to form $\mathrm{Cr}$-rich spinel precipitates. Then oxygen continued to diffuse in order to encircle whole grains thus resulting in further oxidation gradually. Zhong [20] also found that some small oxide precipitates formed along the lath boundaries and grain boundaries in the internal oxidation zone when ferriticmartensitic steel P92 oxidized in SCW. It is well known that the diffusion rate of oxygen along alloy grain boundaries is much higher than that along alloy grain. The oxygen source for the diffusion along alloy grain boundaries is water dissociation $\left(\mathrm{H}_{2} \mathrm{O}=\mathrm{H}_{2}+1 / 2 \mathrm{O}_{2}\right)$. It is inevitable that oxygen penetrated into the substrate along the grain boundaries, leading to the fact that the grain boundaries were oxidized first. As shown in Figure 9, the outer layer is composed of columnar crystal while the inner spinel layer is composed of small grains. The interface of the outer and inner layer is consistent with the original metal surface, which has been proved by palladium markers experiment [21]. The size of the columnar crystal increased with increasing time, which is consistent with the surface morphology shown in Figure 3. The formation of outer columnar grain might be related to the outwards transport of cation and preferential growth of oxide along free space with lower surface energy $[6,7,16]$. The columnar grains are small due to the high rate of nucleation during the short-term oxidation time. Then columnar grains continue to grow by extension of already existing grains with increasing oxidation time as a result of lateral compressive and longitudinal tensile stresses in the scale.

The theoretical thickness ratio of the outer to the inner oxide layer for T22 can be estimated by eq. (2) [13].

$$
\frac{h_{\mathrm{out}}}{h_{\mathrm{in}}}=\frac{x\left(1+C_{\mathrm{Fe}} / C_{\mathrm{Cr}}\right)}{3}-1
$$

where $h_{\text {out }}$ and $h_{\text {in }}$ are the thickness of the outer and the inner oxide layers $(\mu \mathrm{m})$, respectively. $C_{F e}$ and $C_{C r}$ are the chromium and iron concentrations $\left(\mathrm{mol} / \mathrm{cm}^{3}\right)$ in the alloy respectively. The $\mathrm{Fe}-\mathrm{Cr}$ spinel can be expressed as $\mathrm{Fe}_{3-x} \mathrm{Cr}_{x} \mathrm{O}_{4}$, where $x$ denotes the stoichiometric number. As reported in the previous research [13], the theoretical thickness ratio of the outer to the inner oxide layer for T22 is 1.39. Based on the scale length marked in the SEM images, the average thickness of the inner layer or outer layer can be calculated by measuring three different positions on the oxide scale. According to Table 2, the actual outer/inner thickness ratio gradually closes to that calculated by Eq. (2) with an increase in time at $620^{\circ} \mathrm{C}$. It can be noted that the actual outer/ inner thickness ratio at $10 \mathrm{~h}$ (1.91) badly deviated from the theoretical thickness ratio. Based on the mass balance calculation, the thickness ratio of the outer to the inner oxide layer for T22 is not possibly greater than 1.39. However, as shown in Figures 6 and 8, a certain amount of pores present in the outer layer and the porosity of the outer layer evolved with an increase in oxidation time (Figure 3). The outer oxide layer density is not constant, which may be changed with the porosity. As a result, the thickness of the outer layer with pores must be greater than that in without pores. This will cause high thickness ratio of the outer to the inner layer.

According to the EDS results shown in Figures 7 and 8 , the average $\mathrm{Fe} / \mathrm{Cr}$ atomic ratios of the inner layer are approximately 16:1. Based on the atomic number balance of $\mathrm{Cr}$ and $\mathrm{Fe}$, the molar ratio of $\mathrm{Fe}_{3} \mathrm{O}_{4} / \mathrm{FeCr}_{2} \mathrm{O}_{4}$ in the inner 

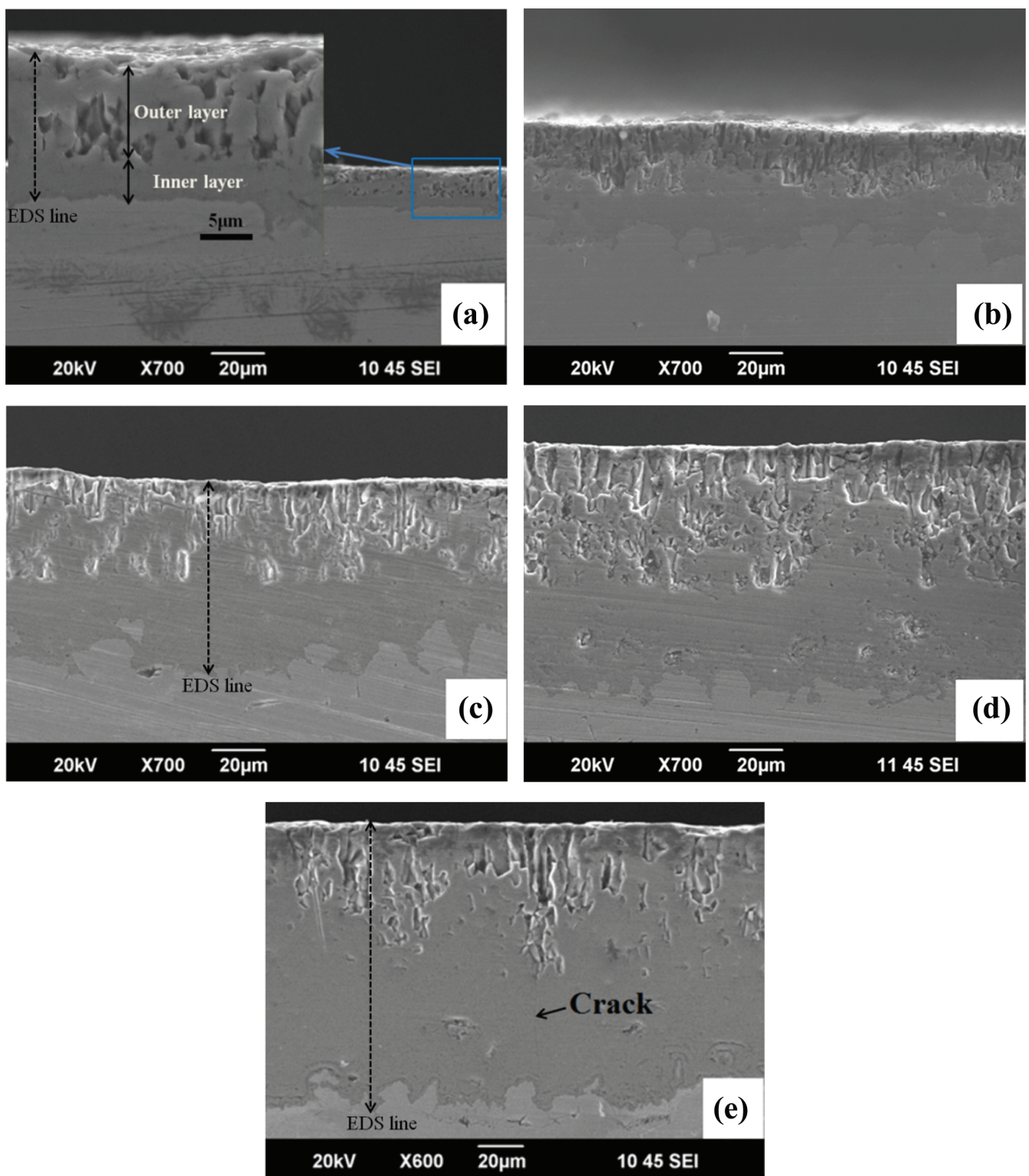

Figure 6: The cross-sectional images of the oxides exposure to SCW at $620^{\circ} \mathrm{C}$ and $25 \mathrm{MPa}$ for $10,80,200,600$ and $1000 \mathrm{~h}$, respectively. (a) $10 \mathrm{~h}$, (b) $80 \mathrm{~h}$, (c) $200 \mathrm{~h}$, (d) $600 \mathrm{~h}$ and (e) $1000 \mathrm{~h}$.

layer was calculated to be 31:3. By considering the molar ratio of $\mathrm{Fe}_{3} \mathrm{O}_{4} / \mathrm{FeCr}_{2} \mathrm{O}_{4}$, the inner density was calculated to be $5.11 \mathrm{~g} / \mathrm{cm}^{3}$.

$$
\rho_{\text {inner }}=n_{\mathrm{Fe}_{3} \mathrm{O}_{4}} \rho_{\mathrm{Fe}_{3} \mathrm{O}_{4}}+n_{\mathrm{FeCr}_{2} \mathrm{O}_{4}} \rho_{\mathrm{FeCr}_{2} \mathrm{O}_{4}}
$$

where $n_{\mathrm{Fe}_{3} \mathrm{O}_{4}}$ and $n_{\mathrm{FeCr}_{2} \mathrm{O}_{4}}$ are the molar ratios of $\mathrm{Fe}_{3} \mathrm{O}_{4}$ and $\mathrm{FeCr}_{2} \mathrm{O}_{4}$ in the inner layer, respectively. $\rho_{\mathrm{Fe}_{3} \mathrm{O}_{4}}\left(5.18 \mathrm{~g} / \mathrm{cm}^{3}\right)$ and $\rho_{\mathrm{FeCr}_{2} \mathrm{O}_{4}}\left(4.45 \mathrm{~g} / \mathrm{cm}^{3}\right)$ are the densities of $\mathrm{Fe}_{3} \mathrm{O}_{4}$ and $\mathrm{FeCr}_{2} \mathrm{O}_{4}$, respectively. Weight gain occurred due to oxygen absorption during exposure, which was estimated by the following equation [10].

$$
\Delta w=\rho_{\text {out }} h_{\text {out }} \frac{M_{\mathrm{O}_{-} \text {out }}}{M_{\mathrm{Fe}_{3} \mathrm{O}_{4}}}+\rho_{\text {inner }} h_{\text {inner }} \frac{M_{\mathrm{o} \text {-inner }}}{M_{\mathrm{Fe}_{3} \mathrm{O}_{4}-\mathrm{FeCr}_{2} \mathrm{O}_{4}}}
$$

where $\Delta w$ is the amount of absorbed oxygen, $\rho_{\text {out }}$ and $\rho_{\text {inner }}$ are the outer and inner layer density respectively, $h_{\text {out }}$ and $h_{\text {inner }}$ are the outer and inner layer thickness respectively, $M_{\mathrm{O}-\text { out }}$ and $M_{0 \text {-inner }}$ are the mole mass of oxygen in $\mathrm{Fe}_{3} \mathrm{O}_{4}$ and $\mathrm{Fe}_{3} \mathrm{O}_{4}-\mathrm{FeCr}_{2} \mathrm{O}_{4}$, respectively. $M_{\mathrm{Fe}_{3} \mathrm{O}_{4}}$

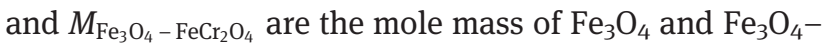
$\mathrm{FeCr}_{2} \mathrm{O}_{4}$, respectively. It is noticeable to consider dissolved species that might release into the water from 

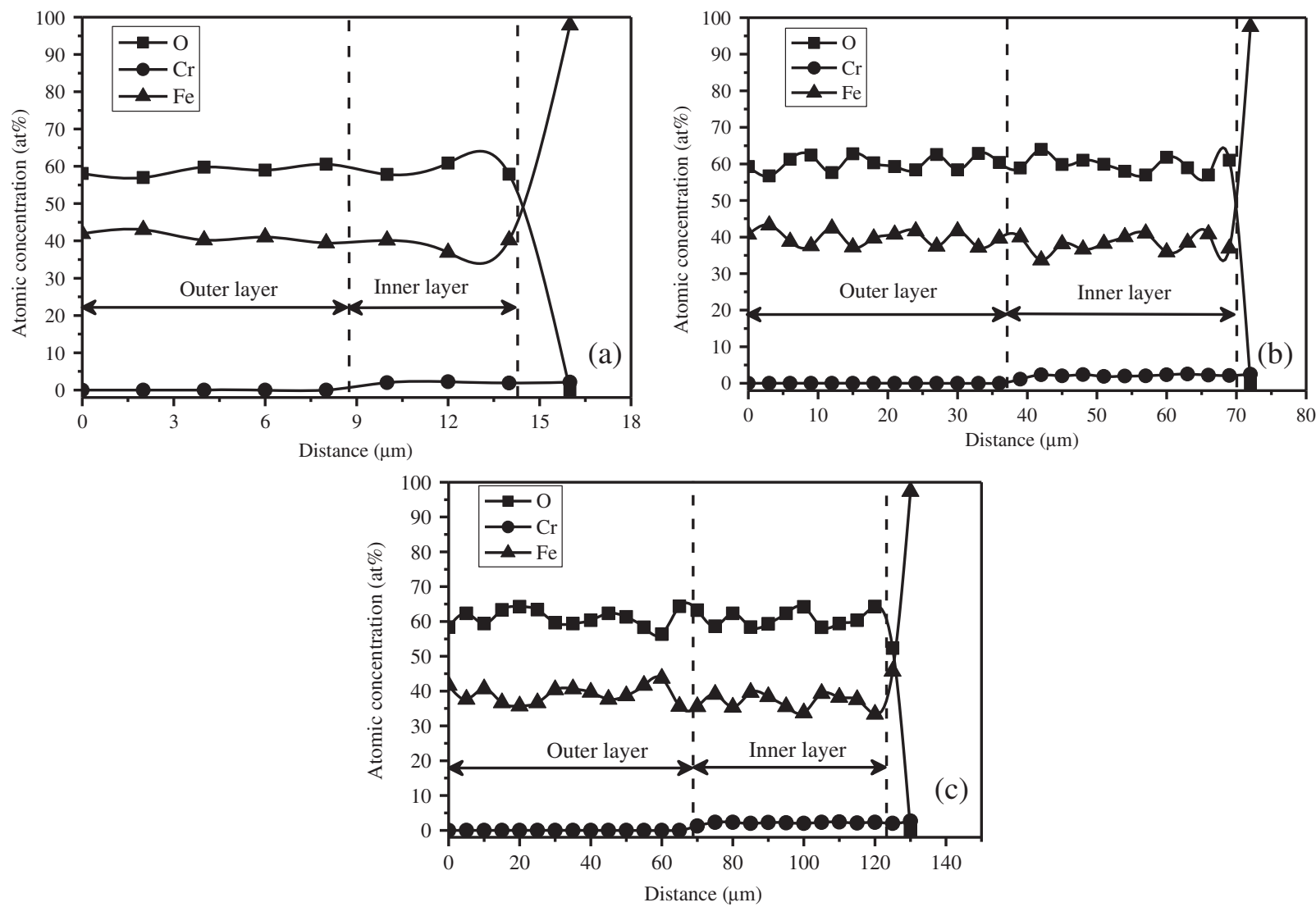

Figure 7: EDS profiles across the oxide layer formed on T22 steel surface exposure to SCW at $620^{\circ} \mathrm{C}$ and $25 \mathrm{MPa}$ for different time. (a) $10 \mathrm{~h}$, (b) $200 \mathrm{~h}$, (c) $1000 \mathrm{~h}$.

metal surfaces during oxidation in subcritical condition. However, SCW behaves like a non-polar solvent, compounds (such as uncharged and ionic $\mathrm{Fe} / \mathrm{Cr}$ species) that are typically soluble become immiscible in SCW. As a result, metallic dissolution can be neglected because of a very low solubility in SCW. Table 2 also shows the measured and calculated mass gains of the samples exposed to SCW at $540-620^{\circ} \mathrm{C}$. Furthermore, the calculated weight gain data are very close to that obtained by weighing at $540-620^{\circ} \mathrm{C}$. This implies that the corrosion behavior of the T22 steel in SCW is similar to that in a gaseous environment where only solid growth takes place without any metallic dissolution. The similar phenomenon was also reported by Yin [10]. Based on the above fact, all the iron stemming from the T22 substrate consume in the whole oxide layer while all the chromium stemming from the T22 substrate only consume in the inner layer, which is consistent with the low diffusion rate of $\mathrm{Cr}$ and high diffusion rate of $\mathrm{Fe}$ [22]. Compared with measured weight gain, the slight increase of calculated weight gain may be related to the high thickness ratio of the outer to the inner layer.
A comparison of the oxidation rates of T22, $\mathrm{P} 92$ and 316 L SS exposed to SCW at $600^{\circ} \mathrm{C}$ have been performed [23, 24]. The weight gain was the lowest for 316 L SS, while T22 exhibited the greatest oxidation rate, followed by $\mathrm{P} 92$. The dominant phases of $316 \mathrm{~L} \mathrm{SS}$ steel at $600^{\circ} \mathrm{C} \mathrm{SCW}$ for $1000 \mathrm{~h}$ were $\mathrm{Cr}_{2} \mathrm{O}_{3}, \mathrm{Fe}_{3} \mathrm{O}_{4}$ and $\mathrm{Fe}-\mathrm{Cr}$ spinel. Only $\mathrm{Fe}_{3} \mathrm{O}_{4}$ and $\mathrm{Fe}-\mathrm{Cr}$ spinel were detected for T22 and P92. The phase composition has an essential influence on the oxidation rate of different steels. Many oxidation mechanisms proposed that the outer layer grows at the oxide/water interface due to the transport of Fe ions through the inner oxide layer, and the Cr-rich spinel oxide grows at the oxide/metal interface due to the inward transport of oxygen and water [12, 14, 24]. In Robertson's [25, 26] model for aqueous oxidation, it is assumed that the corrosion rate is limited by cation diffusion in the inner layer. The increase of $\mathrm{Cr}$ content in $\mathrm{Fe}-\mathrm{Cr}$ spinel resulted in lower diffusion rate of metal. It is reasonable because the Fe-tracer diffusion coefficient decreases with increasing $\mathrm{Cr}$ concentration in the $\mathrm{Fe}-\mathrm{Cr}$ spinel. The $\mathrm{Cr}$ rich spinel plays a decisive role in the oxidation rate of the metal. The $\mathrm{Cr}$ content in the inner layer increases with an increase in Cr content in steel (T22<P92<316 L SS). Especially 

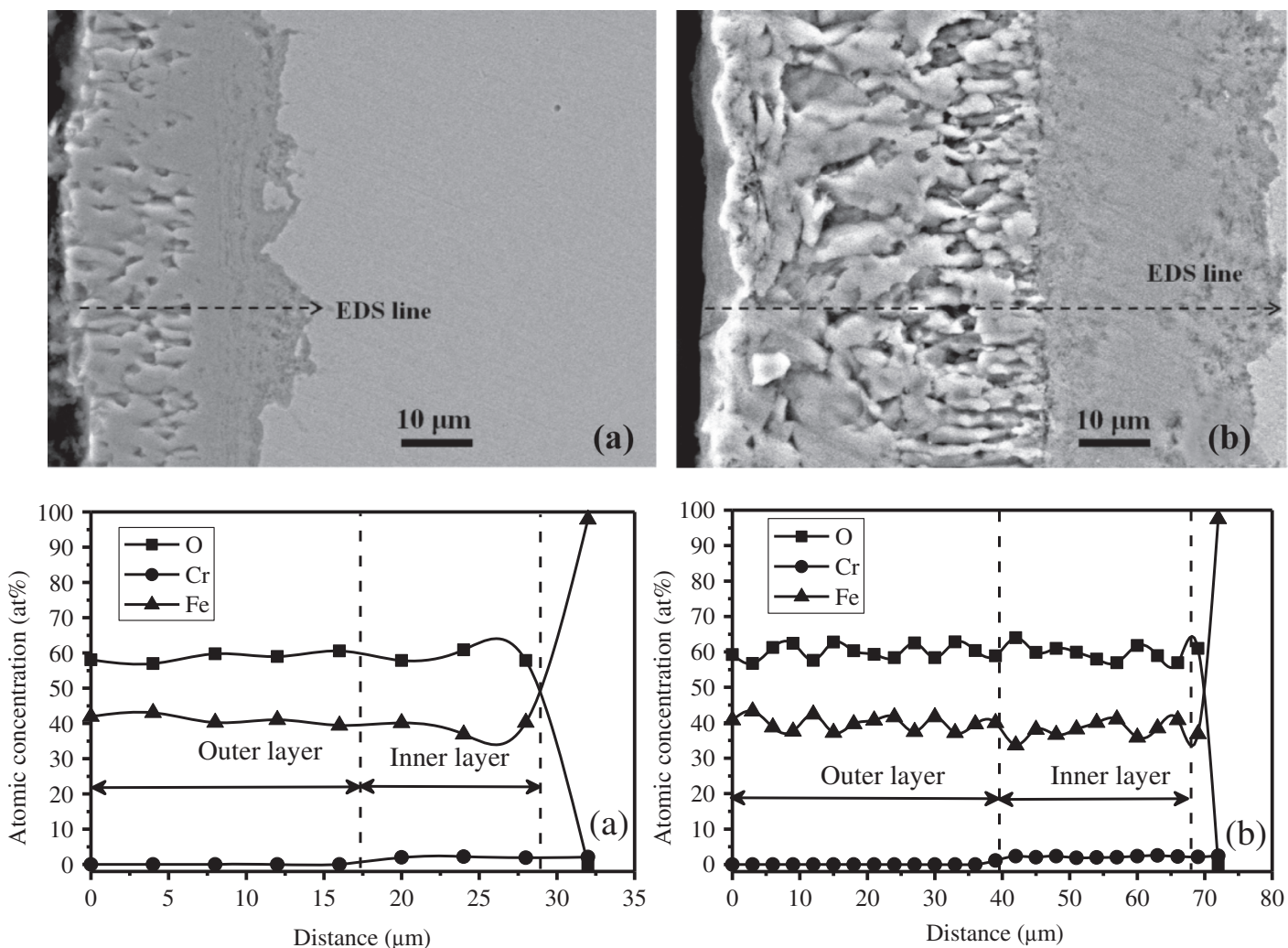

Figure 8: The cross-sectional images and EDS profiles of the oxides exposure to SCW for $1000 \mathrm{~h}$. (a) $540^{\circ} \mathrm{C}$, (b) $600^{\circ} \mathrm{C}$.
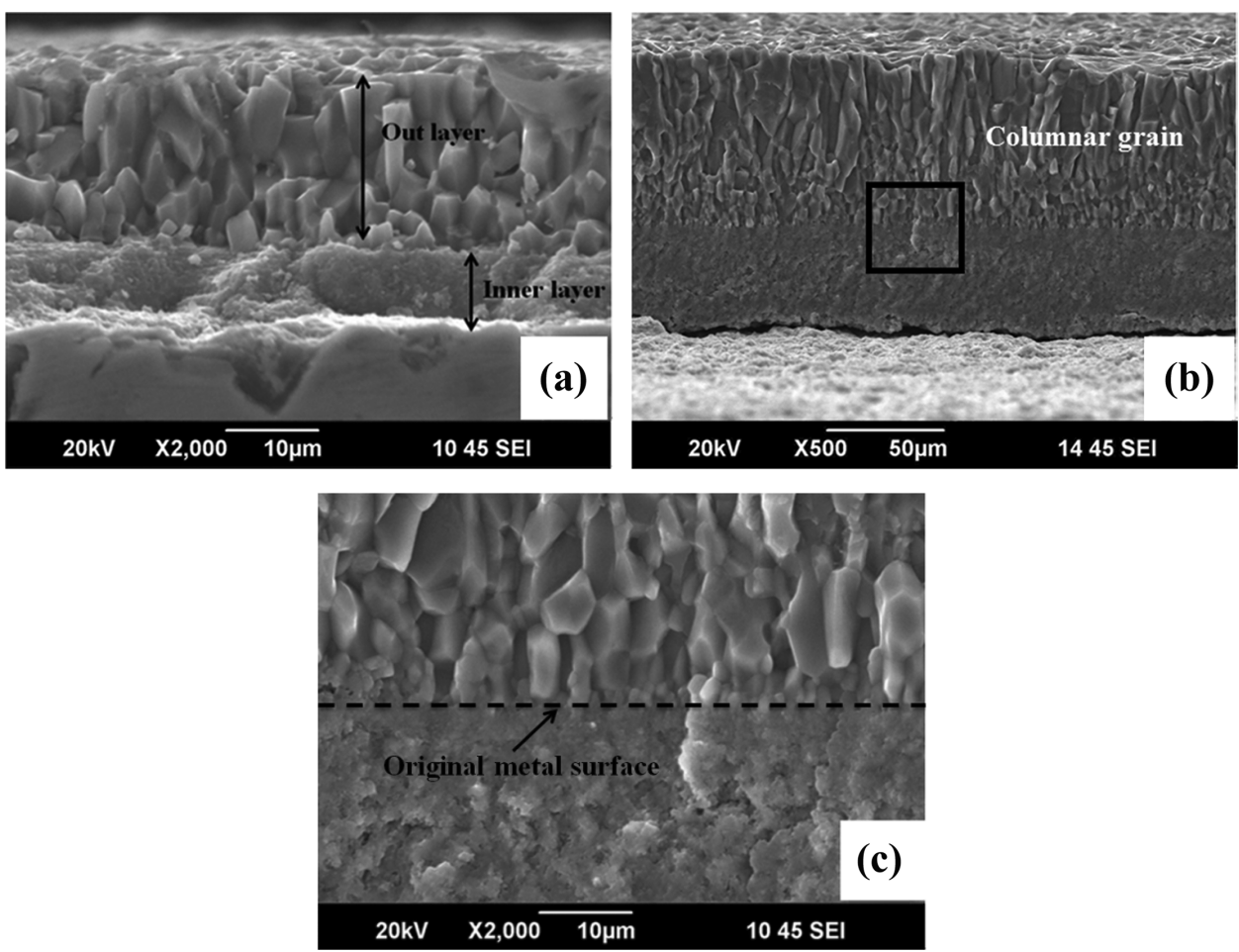

Figure 9: SEM images of the fractured cross-section of T22 sample exposed to SCW. (a) $540^{\circ} \mathrm{C}$ for $1000 \mathrm{~h}$, (b) $620^{\circ} \mathrm{C}$ for $1000 \mathrm{~h}$, (c) higher magnification view of region in (b) (Black box). 
Table 2: Summary of the thickness of oxide, the thickness ratio of the outer layer to the inner layer and weight gain at different oxidation time.

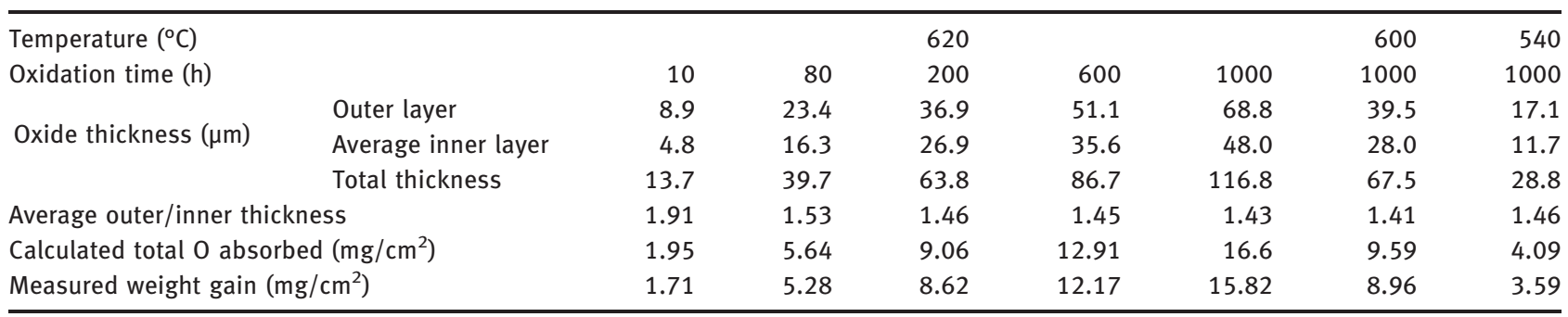

$\mathrm{Cr}_{2} \mathrm{O}_{3}$ was also observed for $316 \mathrm{~L}$ SS, which further improved oxidation resistance. As a result, these alloys can be ranked in increasing order of oxidation resistance: T22<P92<316 L SS.

\section{Conclusions}

The oxidation behavior of Ferritic Steel T22 exposed to SCW at $540-620^{\circ} \mathrm{C}$ and $25 \mathrm{MPa}$ was investigated for up to exposure time of $1000 \mathrm{~h}$. The weight gain indicated that oxidation kinetics obeyed a near-parabolic law at $620^{\circ} \mathrm{C}$. Oxide films formed on T22 have a double-layered structure with an outer layer consisting of $\mathrm{Fe}_{3} \mathrm{O}_{4}$ and an inner layer consisting of spinel oxide. Because of the fast outward diffusion of $\mathrm{Fe}$ along grain boundary rather than grain, pores on the surface of the T22 formed at the initial oxidation stage. The porosity of the outer layer results in the higher thickness ratio of the outer layer to the inner layer. The corrosion mechanism for T22 exposed in SCW is suggested as oxygen absorption without metallic dissolution.

Further research is needed to understand the mechanism behind the observed effects of DO, pressure and applied stress on high-temperature oxidation behaviors of T22 in SCW environments.

Acknowledgements: This paper was supported by the Fundamental Research Funds for the Central Universities (2018QN012), National Natural Science Foundation of China (51471069), Natural Science Foundation of Beijing (2152029), Science and Technology Program of Beijing (Z181100005218006), Postdoctoral Science Foundation of China (2018M641291).

\section{References}

[1] I. Pioro, U. Zirn, R. Duffey, M. Naidin, S. Mokry, Y. Gospodinov and F. Baig, HEFAT (2008).
[2] M. Lukaszewicz, N.J. Simms, T. Dudziak and J.R. Nicholls, Oxid. Met., 79 (2013) 473-483.

[3] N.Q. Zhang, H. Xu, B.R. Li, Y. Bai and D.Y. Liu, Corros. Sci., 56 (2012) 123-128.

[4] H. Xu, Z.L. Zhu and N.Q. Zhang, Oxid. Met., 82 (2014) 21-31.

[5] Y. Chen, K. Sridharan and T. Allen, Corros. Sci., 48 (2006) 2843-2854.

[6] X. Ren, K. Sridharan and T.R. Allen, J. Nucl. Mater., 358 (2006) 227-234.

[7] L. Tan, Y. Yang and T.R. Allen, Corros. Sci., 48 (2006) 3123-3138.

[8] G.S. Was and T.R. Allen, In Proceedings of ICAPP'05, American Nuclear Society (2005).

[9] L. Tan, X. Ren and T.R. Allen, Corros. Sci., 52 (2010) 1520-1528.

[10] K. Yin, S. Qiu, R. Tang, Q. Zhang and L. Zhang, J. Supercrit. Fluids., 50 (2009) 235-239.

[11] M.G. Angell, S.K. Lister and A. Rudge, In 15th International Conference on the Properties of Water and Steam (ICPWS XV), September 8-11, Berlin (2008), pp. 8-11.

[12] J. Bischoff, A.T. Motta, C. Eichfeld, R.J. Comstock, G. Cao and T.R. Allen, J. Nucl. Mater., 441 (2013) 604-611.

[13] N.Q. Zhang, Z.L. Zhu, H. Xu, X.P. Mao and J. Li, Corros. Sci., 103 (2016) 124-131.

[14] Z. Zhu, H. Xu, D. Jiang, X. Mao and N. Zhang, Corros. Sci., 11 (2016) 172-179.

[15] B. Borie, Acta Crystallogr., 13 (1960) 542-545.

[16] J. Stringer, Corros. Sci., 10 (1970) 513-543.

[17] T.I. Barry, A.T. Dinsdale, J.A. Gibsy, B. Hallstedt, M. Hillert, B. Jansson and J.R. Taylor, A Thermodynamic Analysis of the System Fe-Cr-Ni-CO Petten Symposium on Phase Diagrams, Institute of Metals., Washington (1990).

[18] J. Jianmin, M. Montgomery, O.H. Larsen and S.A. Jensen, Mater. Corros., 56 (2005) 459-467.

[19] A.N. Hansson, H. Danielsen, F.B. Grumsen and M. Montgomery, Mater. Corros., 61 (2010) 665-675.

[20] X. Zhong, X. Wu and E.H. Han, Corros. Sci., 90 (2015) $511-521$.

[21] J. Bischoff and A.T. Motta, J. Nucl. Mater., 424 (2012) 261-276.

[22] L. Martinelli, F. Balbaud-Célérier, A. Terlain, S. Bosonnet, G. Picard and G. Santarini, Corros. Sci., 50 (2008) 2537-2548.

[23] Z. Zhu, H. Xu, D. Jiang and N. Zhang, Oxid. Met., 86 (2016) 483-496.

[24] X. Guo, K. Chen, W. Gao, Z. Shen, P. Lai and L. Zhang, Corros. Sci., 127 (2017) 157-167.

[25] J. Robertson, Corros. Sci., 29 (1989) 1275-1291.

[26] J. Robertson, Corros. Sci., 32 (1991) 443-465. 